\title{
Valores de referência do tempo de protrombina (TP) e tempo de tromboplastina parcial ativada (TTPa) em cães
}

\author{
Reference ranges of prothrombin time (PT) and activated partial \\ thromboplastin time (aPTT) in dogs
}

\author{
Sonia Terezinha dos Anjos Lopes ${ }^{1}$ Mauren Picada Emanuelli ${ }^{2}$ Claudete Schmidt $^{3}$ \\ Alceu Gaspar Raiser ${ }^{3}$ Alexandre Mazzanti ${ }^{3}$ Aline Souza Alves ${ }^{4}$
}

RESUMO

\begin{abstract}
Os fatores de coagulação são parte integrante da hemostasia normal, e tanto as coagulopatias hereditárias como adquiridas que envolvem este sistema são de grande importância veterinária, geralmente evidenciadas por manifestações clínicas, tais como, petéquias, equimoses, hematomas e sangramentos tardios. O presente trabalho teve por objetivo a determinação dos valores de referência do tempo de protrombina $(T P)$ e tempo de tromboplastina parcial ativada (TTPa), por métodos manuais. Para tanto, utilizou-se "kits" para dosagens humanas, devido à inexistência de produtos similares de uso específico veterinário. Foram utilizados 40 cães clinicamente sadios, sem raça definida, machos ou fêmeas, de diferentes idades. As amostras sanguíneas foram de 2,5ml cada, colhidas por venopunção cefálica e acondicionadas em tubos de centrífuga contendo $0,25 \mathrm{ml}$ de citrato de sódio a $3,8 \%$. O plasma foi imediatamente separado por centrifugação e as determinações de TP e TTPa foram realizadas utilizando-se "kits" comerciais "HemoStat Thromboplastin-SI $a^{a}$ e "HemoStat aPTT-El $l^{\text {", }}$ respectivamente. Os resultados obtidos foram de 6,87 $\pm 1,4$ segundos para o TP com valores mínimo e máximo de 4,07 e 9,67, respectivamente, $e$ de 15,10 \pm 1,6 segundos para TTPa com valores mínimo e máximo de 11,9 e 18,3, respectivamente. Conclui-se, que os valores obtidos neste trabalho podem ser utilizados como referência. Os reagentes utilizados para plasma humano podem ser empregados para o plasma de cães.
\end{abstract}

Palavras-chave: hemostasia, patologia clínica, tempo de coagulação.

\section{ABSTRACT}

The coagulation factors are part of normal hemostasis, and both hereditary and acquired coagulopathies that involve this system have an important role in veterinary medicine, generally evidenced by clinical signs such as: petechias, ecchymosis, hematomas and late hemorrhagies. The objective of this experiment was to determine reference range values of prothrombin time $(P T)$ and activated partial thromboplastin time (aPTT), for manual methods. Human commercial kits were used because there are no available veterinary kits for this purpose. Forty healthy dogs, with no definite breed, male or female, with variable age were used. The blood samples were $2.5 \mathrm{ml}$, harvested by cephalic venipuncture, and stored in tubes containing $0.25 \mathrm{ml}$ of sodium citrate $3.8 \%$. Total blood was centrifuged and plasma separated. PT and aPTT were determinate using commercial kits, "HemoStat Thromboplastin-Sia" and "HemoStat aPTT-El", respectively. The results ranged from $6.87 \pm 1.4$ seconds for $P T$, with a minimum and a maximum of 4.07 and 9.67, respectively, and $15.1 \pm 1.6$ seconds for aPTT, with a minimum and a maximum of 11.9 and 18.3 , respectively. As a conclusion, these results can be used as reference values. These human commercial kits can be used for determination in dogs.

Key words: hemostasis, clinical pathology, coagulation time.

\section{INTRODUÇÃO}

No processo de hemostasia, logo após a lesão vascular, ocorre vasoconstrição reflexa local, o que reduz instantaneamente o fluxo de sangue no local. Em seguida, as plaquetas interagem com o local da lesão, formando o tampão plaquetário primário, caracterizando a fase primária da hemostasia. Este tampão inicialmente é frouxo, porém, geralmente satisfatório para o controle da hemorragia se a lesão

\footnotetext{
${ }^{1}$ Médico Veterinário, Doutor, Docente do Departamento de Clínica de Pequenos Animais (DCPA), Hospital Veterinário, Universidade Federal de Santa Maria (UFSM), 97105-900, Santa Maria, RS. Email: Sonia@ smail.ufsm.br Autor para correspondência.

${ }^{2}$ Médico Veterinário do Hospital Veterinário, Universidade de Cruz Alta (UNICRUZ).

${ }^{3}$ Médico Veterinário, Doutor, Professor titular, DCPA, UFSM.

${ }^{4}$ Médico Veterinário, doutor, docente, UNICRUZ.
} 
vascular for pequena. A ativação da cascata da coagulação resulta na formação de fibrina que estabiliza o tampão plaquetário primário, promovendo a formação do coágulo. A cascata da coagulação consiste na via intrínseca e na via extrínseca que convergem numa via comum a qual termina na formação do complexo denominado ativador da protrombina. Este, em presença de quantidade suficiente de $\mathrm{Ca}^{++}$iônico, promove a conversão da protrombina em trombina. A trombina converte o fibrinogênio em monômeros de fibrina, que envolvem as plaquetas, as células sangüíneas e o plasma, para formar o coágulo, caracterizando a fase secundária da hemostasia (JAIN, 1993; RAND et al., 1996; DODDS, 1997; GREEN \& THOMAS, 1997; TROY, 1998; GUYTON \& HALL, 2002).

As coagulopatias hereditárias, assim como anormalidades adquiridas da hemostasia secundária, como coagulação intravascular disseminada (CID), intoxicação por raticidas e hepatopatias são comumente vistas em cães (GREEN, 1980; GREEN \& THOMAS, 1997; TSENG et al., 2001). É importante a integridade da cascata da coagulação para a hemostasia perfeita e a deficiência de qualquer um dos fatores da coagulação pode resultar em hemorragias (GUYTON \& HALL, 2002). O sangramento espontâneo, de surgimento mais tardio, e de duração mais prolongada, causando hematomas, hemartrose ou hemorragia nos tecidos profundos ou cavidades corporais está ligado a distúrbios da formação do tampão hemostático secundário, que ocorre em pacientes com deficiências de fatores da coagulação (GREEN \& THOMAS, 1997).

Os testes de monitoramento da coagulação envolvem a ativação in vitro de partes da cascata de coagulação e medem o tempo até a formação do coágulo (TSENG et al., 2001). O tempo de protrombina (TP) é usado para avaliar as vias extrínseca (fator VII) e comum (fatores X, V, II e I), enquanto o tempo de tromboplastina parcial ativada (TTPa) é usado para monitorar as vias intrínseca (fatores XII, XI, IX e VIII) e comum (JAIN, 1993; RAND et al., 1996; DODDS, 1997; GREEN \& THOMAS, 1997; COUTO, 1999).

Os reagentes utilizados para determinar o TP e o TTPa são desenvolvidos para determinação em plasma humano (GREENE et al., 1981), e são adaptados para uso em cães. Os "kits" permitem a determinação quantitativa manual ou automática do TP e do TTPa. Estudos recentes vêm utilizando métodos automáticos e comparando-os com os métodos manuais já utilizados (MISCHKE \& NOLTE, 1997; MISCHKE, 2001; TSENG et al., 2001), porém o custo elevado dos aparelhos automáticos restringe o seu uso.

Os valores de referência para TP e TTPa encontrados na literatura para o plasma canino sadio, utilizando reagentes comerciais, varia significativamente. O TP tem uma variação de 5,8 a 14,9 segundos, enquanto o TTPa varia de 11 a 25 segundos, conforme Tabela 1. A variação nos valores encontrados está relacionada a vários fatores como a técnica de coleta, o recipiente de coleta, a concentração de anticoagulante, o reagente, o método, o tempo de incubação, o tempo de armazenamento e a temperatura (NAGHIBI et al., 1988; HASSOUNA, 1993; MONCE et al., 1995). Além destas variações, existem aquelas relacionadas a espécie, raça, sexo, idade, dieta, estado de nutrição entre outros que podem influenciar nas determinações (DUNCAN et al., 1994). Em função de todos estes fatores que podem interferir em sua determinação, é importante determinar valores de referência conforme as condições de cada local (GREENE et al., 1981; DUNCAN et al., 1994; MONCE et al., 1995; TSENG et al., 2001).

O presente trabalho tem como objetivo determinar valores de referência para TP e TTPa em cães clinicamente sadios, utilizando reagentes para testes de coagulação sangüínea em plasma humano, por métodos manuais.

\section{MATERIAL E MÉTODOS}

Foram utilizados 40 cães clinicamente sadios, sem raça definida, machos ou fêmeas, adultos

Tabela 1 - Valores encontrados para tempo de protrombina (TP) e tempo de tromboplastina parcial ativada (TTPa).

\begin{tabular}{lll}
\hline Autores & \multicolumn{1}{c}{$\begin{array}{c}\text { TP } \\
\text { (segundos) }\end{array}$} & $\begin{array}{c}\text { TTPa } \\
\text { (segundos) }\end{array}$ \\
\hline BADYLAK \& VAN VLEET, 1981 & $5,8-7,6$ & $11,0-16,1$ \\
DUNCAN \& PRASSE, 1982 $^{*}$ & $8,0-13,0$ & $18,0-25,0$ \\
EVANS \& FLYNN, 1992 & & $9,0-14,0^{\mathrm{b}}$ \\
DUNCAN et al., 1994* $^{*}$ & & $7,74-9,26^{\mathrm{b}}$ \\
DODDS, 1997 $^{*}$ & $5,8-7,9$ & $13,1-17,4$ \\
GREEN \& THOMAS, 1997 $^{*}$ & & $14,0-18,0$ \\
MISCHKE \& NOLTE, 1997 $^{1}$ & $6,0-10,0$ & $12,0-16,0$ \\
TSENG et al., 2001 $^{1}$ & $6,28-7,32$ & \\
& $10,5-14,9$ & $10,9-16,9$ \\
MISCHKE et al., 2003 $^{2}$ & $6,6-8,6^{\mathrm{a}}$ & \\
& $6,5-8,5^{\mathrm{a}}$ & \\
LOPES et al., 2004 $^{1}$ & $6,3-7,7^{\mathrm{a}}$ & \\
\hline
\end{tabular}

${ }^{1}$ Método manual.

${ }^{2}$ Método automático ( ${ }^{\mathrm{a}}$ Diferentes reagentes, ${ }^{\mathrm{b}}$ Diferentes aparelhos).

*Método não especificado.

Ciência Rural, v. 35, n. 2, mar-abr, 2005. 
de diferentes idades. As amostras sangüíneas foram de $2,5 \mathrm{ml}$, colhidas por venopunção cefálica e acondicionadas em tubos de centrífuga contendo $0,25 \mathrm{ml}$ de citrato de sódio a $3,8 \%$. O plasma foi imediatamente separado por centrifugação a $2000 \mathrm{rpm}$ por 10 minutos e as determinações de TP e TTPa foram realizadas utilizando-se "kits" comerciais "HemoStat Thromboplastin-SI" e "HemoStat aPTT$\mathrm{EL}^{\mathrm{b}}$ " respectivamente. Todas as amostras foram testadas em duplicata.

Para determinação do TP, foram pipetados $100 \mathrm{~mL}$ do plasma em tubos pré-aquecidos e incubados a $37^{\circ} \mathrm{C}$ por 3 minutos. Após, adicionaram-se $200 \mathrm{~mL}$ do reagente PT-SI (extrato liofilizado de cérebro de coelho e cloreto de cálcio) pré-aquecido a $37^{\circ} \mathrm{C}$, imediatamente foi acionado o cronômetro e registrado o tempo gasto para formação do coágulo.

Para determinação do TTPa, foram pipetados $100 \mathrm{~mL}$ do plasma em tubos pré-aquecidos e incubados a $37^{\circ} \mathrm{C}$ por 1 minuto. Após, adicionaramse $100 \mathrm{~mL}$ do reagente a-PTT-EL (extrato de cérebro de coelho cloroformizado e ácido elágico) e a mistura incubada a $37^{\circ} \mathrm{C}$ por 3 minutos. Por último, foi adicionado o cloreto de cálcio pré-aquecido a $37^{\circ} \mathrm{C}$, imediatamente foi acionado o cronômetro e registrado o tempo gasto para formação do coágulo.

\section{RESULTADOS E DISCUSSÃO}

Os resultados obtidos para o TP variaram de 4,07 a 9,67 segundos, com média de 6,87 $\pm 1,4$. BADYLAK \& VAN VLEET (1981), MISCHKE \& NOLTE (1997) e TSENG et al. (2001), utilizando métodos manuais e "kits" diferentes do utilizado neste trabalho, obtiveram valores mínimos mais elevados. BADYLAK \& VAN VLEET (1981) e MISCHKE \& NOLTE (1997), encontraram valores máximos menores, enquanto TSENG et al. (2001), obtiveram valores maiores. DUNCAN \& PRASSE (1982), DUNCAN et al. (1994) e GREEN \& THOMAS (1997), sem a especificação do método e "kits" utilizados, encontraram valores mínimos maiores. DUNCAN \& PRASSE (1982) e GREEN \& THOMAS (1997) obtiveram valores máximos mais elevados, enquanto DUNCAN et al. (1994) obtiveram valores máximos menores. MISCHKE et al. (2003), utilizando diferentes "kits" e método automático, encontraram valores mínimos mais elevados, sendo que os valores máximos foram inferiores aos encontrados no presente trabalho.

Para TTPa os valores encontrados variaram de 11,9 a 18,3 segundos, com média de 15,10 \pm 1,6. EVANS \& FLYNN (1992), utilizando diferentes tempos de incubação (10 e 2 minutos) e diferentes métodos automáticos ("Coagulyser" e "KC 10 Coagulometer"), obtiveram valores máximos e mínimos (Tabela 1) inferiores aos encontrados neste estudo. BADYLAK \& VAN VLEET (1981), DUNCAN \& PRASSE (1982), DUNCAN et al. (1994), DODDS (1997) e GREEN \& THOMAS (1997) encontraram valores mínimos superiores ao encontrado neste trabalho. Os valores máximos citados por BADYLAK \& VAN VLEET (1981) e GREEN \& THOMAS (1997) foram menores, enquanto DUNCAN \& PRASSE (1982), DUNCAN et al. (1994) e DODDS (1997) encontraram valores mais elevados.

Estes resultados vêm comprovar a necessidade de se determinar valores de referência, conforme citaram GREENE et al. (1981), DUNCAN et al. (1994), MONCE et al. (1995) e TSENG et al. (2001), uma vez que estes valores estão relacionados a vários fatores, como: reagentes, temperatura e método utilizado (NAGHIBI et al., 1988; HASSOUNA, 1993; MONCE et al., 1995). Também os reagentes comerciais utilizados para os testes de coagulação foram desenvolvidos em condições ótimas para o plasma humano. Diante da inexistência destes reagentes, específicos para uso veterinário, faz-se necessária a determinação dos efeitos dos reagentes e as condições de reações nos tempos dos testes de coagulação para todas as espécies.

Os tempos de TP do plasma canino são inferiores (aproximadamente 7 segundos) aos tempos de TP do plasma humano (aproximadamente 12 segundos), com se observou neste estudo. Isto provavelmente ocorre pela atividade oito vezes maior do fator V e quatro vezes maior do fator VII no plasma canino (MISCHKE \& NOLTE, 1997).

Segundo NOGUCHI et al. (1989), a atividade total dos fatores de contato, fatores XII e XI, cininogênio e pré-calicreína, foram maiores no plasma canino que no plasma humano, podendo ser responsáveis pelas variações encontradas para o TTPa determinados por diferentes métodos.

\section{CONCLUSÃO}

Os valores de tempo de protrombina e de tempo de tromboplastina parcial ativada obtidos no presente trabalho podem ser utilizados como de referência. Os reagentes utilizados para plasma humano podem ser empregados para o plasma de cães.

\section{FONTES DE AQUISIÇÃO}

a,b - IN VITRO DIAGNOSTICA LTDA, Rua Cromita, 278, Distrito Industrial, Itabira, 35900-970, MG.

Ciência Rural, v. 35, n. 2, mar-abr, 2005. 


\section{REFERÊNCIAS BIBLIOGRÁFICAS}

BADYLAK, S.F.; VAN VLEET, J.F. Alterations of prothrombin time and activated partial thromboplastin time in dogs with hepatic disease. Am J Vet Res, v.42, n.12, p.2053-2056, 1981.

COUTO, C.G. Clinical approach to the bleeding dog or cat. Vet Med, v.94, p.450-459, 1999.

DODDS, W.J. Hemostasis. In: KANEKO, J.J. et al. Clinical biochemistry of domestic animals. San Diego : Academic, 1997. Cap.10, p.241-283.

DUNCAN, J.R.; PRASSE, K.W. Valores normais. In: Patologia clínica veterinária. Rio de Janeiro : Guanabara Koogan, 1982. Apêndice I, p.165-170.

DUNCAN, J.R., et al. Quality control, test validity, and reference values. In . Veterinary laboratory medicine - clinical pathology. 3.ed. Iowa : Iowa State University, 1994. Cap.13, p.229-234

EVANS, G.O.; FLYNN, R.M. Activated partial thromboplastin time mensurements in citrated canine plasma. J Comp Path, v.106, p.79-82, 1992.

GREEN, R.A. Activated coagulation time in monitoring heparinized dogs. Am J Vet Res, v.41, p.1793-1797, 1980 .

GREEN, R.A.; THOMAS, J.S. Distúrbios hemostáticos: coagulopatias e trombose. In: ETTINGER, S.J.; FELDMAN, E.C Tratado de medicina interna veterinária - moléstias do cão e do gato. 4.ed. São Paulo : Manole, 1997. V.2, cap.145, p.26902714

GREENE, C.E. et al. Coagulation studies of plasmas from healthy domesticated animals and persons. Am J Vet Res, v.42, n.12, p.2170-2177, 1981.

GUYTON, A.C.; HALL, J.E. Hemostasia e coagulação sangüínea. In: . Tratado de fisiologia médica. 10.ed. Rio de Janeiro: Guanabara Koogan, 2002. Cap.36, p.394-404.
HASSOUNA, H.I. Laboratory evaluation of hemostatic disorders. Hematol Oncol Cli North Am, v.7, p.1161-1222, 1993.

JAIN, N.C. Coagulation and its disorders. In: Essentials of veterinary hematology. Philadelphia : Lea \& Febiger, 1993. Cap.5, p.82-104.

MISCHKE, R.; NOLTE, I. Optimization of prothrombin time measurements in canine plasma. Am J Vet Res, v.58, n.3, p.236241, 1997.

MISCHKE, R. Optimization of coagulometric tests that incorporate human plasma for determination of coagulation factor activities in canine plasma. Am J Vet Res, v.62, n.4, p.625-629, 2001

MISCHKE, R. et al. Sensitivity of different prothrombin time assays to factor VII deficiency in canine plasma. Veterinary Journal, v.166, p.79-85, 2003.

MONCE, K.A. et al. Evaluation of a commercially available prothrombin time assay kit for use in dogs and cats. J Am Vet Med Assoc, v.207, p.581-584, 1995.

NAGHIBI, F. et al. Effects of reagent and instrument on prothrombin times and activated partial thromboplastin times and patient/control ratios. Thromb Haemost, v.59, p.455-463, 1988.

NOGUCHI, M. et al. Comparative studies of measuring condition of activated partial thromboplastin time and contact factors in experimental animals. Experimental Animals, v.38, p.221-229, 1989.

RAND, M.L. et al. Plasma proteins, immunoglobulins, \& blood coagulation. In: Harper's biochemistry. 24.ed. Samford : Appleton \& Lange, 1996. Cap.59, p.707-732.

TROY, G.C. An overview of hemostasis. Vet Clin North Am Small Anim Pract, v.28, p.483-513, 1998.

TSENG, L.W. et al. Evaluation of a point-of-care coagulation analyzer for measurement of prothrombin time, activated partial thromboplastin time, and activated clotting time in dogs. Am J Vet Res, v.62, n.9, p.1455-1460, 2001. 